\title{
Unilateral versus bilateral antegrade cerebral protection during circulatory arrest in aortic surgery: A meta-analysis of 5100 patients
}

\author{
Emiliano Angeloni, MD, ${ }^{\mathrm{a}}$ Umberto Benedetto, $\mathrm{PhD},{ }^{\mathrm{a}}$ Johanna J. M. Takkenberg, $\mathrm{PhD},{ }^{\mathrm{b}}$ \\ Ivan Stigliano, MD, ${ }^{\mathrm{a}}$ Antonino Roscitano, $\mathrm{MD},{ }^{\mathrm{a}}$ Giovanni Melina, $\mathrm{PhD},{ }^{\mathrm{a}}$ and Riccardo Sinatra, $\mathrm{MD}^{\mathrm{a}}$
}

\begin{abstract}
Objective: Our objective was to determine whether the use of unilateral (u-ACP) or bilateral antegrade cerebral perfusion (b-ACP) results in different mortality and neurologic outcomes after complex aortic surgery.
\end{abstract}

\begin{abstract}
Methods: PubMed, Embase, and the Cochrane Library were searched for studies reporting on postoperative mortality and permanent (PND) and temporary neurologic dysfunction (TND) in complex aortic surgery requiring circulatory arrest with antegrade cerebral protection. Analysis of heterogeneity was performed with the Cochrane Q statistic.
\end{abstract}

Results: Twenty-eight studies were analyzed for a total of 1894 patients receiving u-ACP versus 3206 receiving b-ACP. Pooled analysis showed similar rates of 30-day mortality $(8.6 \%$ vs $9.2 \%$ for u-ACP and b-ACP, respectively; $P=.78)$, PND $(6.1 \%$ vs $6.5 \% ; P=.80)$, and TND $(7.1 \%$ vs $8.8 \% ; P=.46)$. Age, sex, and cardiopulmonary bypass time did not influence effect size estimates. Higher rates of postoperative mortality and PND were among nonelective operations and for highest temperatures and duration of the circulatory arrest. The Egger test excluded publication bias for the outcomes investigated.

Conclusions: This meta-analysis shows that b-ACP and u-ACP have similar postoperative mortality and both PND and TND rates after circulatory arrest for complex aortic surgery. (J Thorac Cardiovasc Surg 2014;147:60-7)

Postoperative neurologic dysfunction, either permanent (PND) or temporary (TND), after aortic surgery can be a devastating complication that significantly increases length of stay and mortality. ${ }^{1,2}$

The backbone of cerebral protection during systemic aortic surgery requiring circulatory arrest (CA) is hypothermic $\mathrm{CA},{ }^{3}$ but several drawbacks of this technique have been extensively documented: temperature-related organ hypoperfusion, ${ }^{4}$ impairment of cerebral autoregulation, ${ }^{5}$ and increased risk of neurologic complications beyond $40 \mathrm{~min}$ utes. ${ }^{6}$ Therefore, cerebral perfusion was introduced and widely adopted in association with deep hypothermic $\mathrm{CA}^{7,8}$ Nowadays, the need for deep hypothermia has been questioned and antegrade cerebral perfusion (ACP) has been shown to provide long and safe periods of CA also when used in combination with moderate hypothermic CA. ${ }^{9}$ In addition, in the context of ACP,

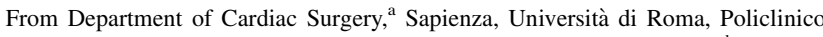
Sant'Andrea, Rome, Italy; and Department of Cardiothoracic Surgery, ${ }^{\mathrm{b}}$ Erasmus University Medical Center, Rotterdam, The Netherlands.

Disclosures: Authors have nothing to disclose with regard to commercial support.

This paper was a Presentation on Demand at the AATS Aortic Symposium 2012 in New York, NY.

Received for publication July 17, 2012; revisions received Sept 15, 2012; accepted for publication Oct 16, 2012; available ahead of print Nov 12, 2012

Address for reprints: Emiliano Angeloni, MD, Department of Cardiac Surgery, Sapienza, Università di Roma, Policlinico Sant'Andrea, Via di Grottarossa 1035, 00189, Roma, Italia (E-mail: emilianoangeloni@gmail.com).

$0022-5223 / \$ 36.00$

Copyright (c) 2014 by The American Association for Thoracic Surgery http://dx.doi.org/10.1016/j.jtcvs.2012.10.029
}

bilateral perfusion of supra-aortic vessels is still debated. Many centers adopt unilateral antegrade cerebral perfusion (u-ACP) via the right axillary artery without the placement of an additional catheter in the left carotid artery to obtain bilateral ACP (b-ACP). ${ }^{10}$ Advantages of u-ACP consist in its rapidity and in avoiding manipulation of the supraaortic vessels; meanwhile, concerns are about the completeness of the cerebral protection when perfusing the brain from only 1 side.

Comparison of these different strategies of cerebral protection has always been hampered by the wide spectrum of preoperative conditions, pathologic anatomies, complications, and surgical procedures; thus there is no consensus among surgeons concerning the method to gain optimal cerebral protection. The aim of the present meta-analysis was to investigate mortality and neurologic complications after aortic surgery with the use of ACP and to compare these end points between patients receiving $\mathrm{u}-\mathrm{ACP}$ versus b-ACP.

\section{METHODS}

This systematic review and meta-analysis were done with the use of the Meta-analysis Of Observational Studies in Epidemiology (MOOSE) guidelines. $^{11}$

\section{Search Strategy}

On July 17, 2011, a PubMed and Embase search of $<<$ antegrade[All Fields] AND ("cerebrum"[MeSH Terms] OR "cerebrum"[All Fields] OR “cerebral”[All Fields] OR "brain" [MeSH Terms] OR "brain"[All Fields]) AND ("perfusion”"[MeSH Terms] OR "perfusion"[All Fields]) AND protection[All Fields] $>>$ was conducted, limited to publications in humans. In addition, the entire Cochrane Library was searched for 


\section{Abbreviations and Acronyms}

$\mathrm{ACP}=$ antegrade cerebral perfusion

$\mathrm{b}-\mathrm{ACP}=$ bilateral antegrade cerebral perfusion

$\mathrm{CA}=$ circulatory arrest

$\mathrm{CI}=$ confidence interval

PND = permanent neurologic dysfunction

TND $=$ temporary neurologic dysfunction

$\mathrm{u}-\mathrm{ACP}=$ unilateral antegrade cerebral perfusion

(antegrade cerebral perfusion) OR (cerebral protection aortic surgery) in the title, abstract, or key words of publications. Three reviewers (E.A., I.S., and A.R.) screened the titles and abstracts of identified studies. Inclusion criteria were observational studies reporting neurologic complications and mortality after antegrade cerebral protection during CA in the context of aortic surgery as well as study sample size of 20 patients or more. A second independent reviewer (G.M.) assessed whether inclusion and exclusion were performed correctly. In cases of disagreement, an agreement was negotiated. References of selected articles were cross-checked for other relevant studies, and every publication included was reviewed by the local institutional review board.

\section{Data Extraction}

Microsoft Excel and Comprehensive Meta Analysis version 2.0 (2006 Biostat, Inc, Englewood, NJ) were used for data extraction and statistical analysis. The study design was documented. When this could not be done, the study was excluded. When multiple publications on the same patient population were found, the most recent and complete report was selected.

Outcomes investigated were the development of postoperative transient or permanent neurologic dysfunction and of postoperative mortality, as reported in each article.

Inasmuch as 5 studies (Kruger 2011, Lee 2009, Saritas 2010, Estrera 2010, and Khaladj 2008; see Table 1 for references) reported only 30-day mortality and not hospital mortality, a subanalysis omitting the latter papers was performed. Other subanalyses of the outcomes were performed on smaller and more homogeneous cohorts to deal with the potential bias of retrospective studies.

PND (permanent neurologic dysfunction) was defined as a new and permanent focal (stroke) or global (ie, parkinsonism, coma, gait disturbance) neurologic deficit with or without evidence of cerebral infarction/hemorrhage on computed tomography or magnetic resonance imaging and persisting at discharge. Such a diagnosis was confirmed by a neurologist.

TND (temporary neurologic dysfunction) was defined as postoperative confusion, delirium, obtundation, or transient focal deficits (resolution within 24 hours), with negative results of brain computed tomography or magnetic resonance imaging scans.

\section{Statistical Analysis}

Risks of cerebral complications (TND and PND) and mortality for each individual study were pooled on a logarithmic scale with the use of the inverse variance method in a random effects model. When an included study did not specify a particular outcome in the "Methods" section, did not mention it in the "Results" section, or omitted it from both sections, then the study was excluded from analysis of that event. Funnel plots were used to study publication bias. Heterogeneity was assessed with the use of the Cochran $Q$ statistic and the $\mathrm{I}^{2}$ test. To compare $\mathrm{u}-\mathrm{ACP}$ and b-ACP results, we performed a separate analysis of heterogeneity between the 2 groups using the Cochrane Q statistic. Patient age, urgent/emergency indication, cardiopulmonary bypass time, CA time, and CA temperature were explored as potential causes for heterogeneity through subgroup analyses by means of meta-regression analysis using such factors as moderators. Publication bias was detected by the Egger regression test.

\section{RESULTS}

\section{Overview of the Studies Included}

A total of 136 studies were identified; studies were excluded for the following reasons: case reports or fewer than 20 patients included $(n=11)$, pediatric papers $(n=2)$, overlap with other studies $(n=34)$, data on outcomes of interest not reported $(\mathrm{n}=19)$, animal studies $(\mathrm{n}=18)$, review or (invited) comment $(\mathrm{n}=16)$, reports of new/alternative techniques $(n=8)$.

Finally, 28 publications (see Table 1 for references) reporting on 5100 patients (3206 patients receiving b-ACP and 1894 patients receiving $\mathrm{u}-\mathrm{ACP}$ ) were included in the analysis: 3 reported results after both $\mathrm{u}-\mathrm{ACP}$ and $\mathrm{b}-\mathrm{ACP}$, 8 reported results after $\mathrm{U}-\mathrm{ACP}$, and 17 reported results after b-ACP. In the group of b-ACP, cerebral perfusion was achieved by cannulating either the right axillary artery and the left common carotid artery (with or without cannulation of the left sublcavian artery) or directly via the supraaortic vessels. Unilateral cerebral perfusion instead was achieved in most cases by direct or side-graft cannulation of the right axillary artery; in only a few studies the innominate artery (Numata 2009 and some patients from Urbanski 2012) or the right brachial artery (Saritas 2010 and Tasdemir 2002) were used. Flow rates of cerebral perfusion were adjusted according to the neurologic monitoring.

Table 1 provides an overview of the publications obtained by the systematic review, and Table 2 depicts baseline characteristics of the study population stratified for $\mathrm{u}-\mathrm{ACP}$ versus b-ACP.

\section{Meta-Analysis of Outcomes}

Pooled analysis showed similar rates of postoperative mortality: 9.2\% (95\% confidence interval [CI], 6.9-12.2) for b-ACP versus 8.6\% (95\% CI, 5.6-12.9) for u-ACP; $P=.78$ (Figure 1). As for mortality, postoperative incidence of PND also did not differ significantly between groups: $6.5 \%(95 \% \mathrm{CI}, 4.8-9.0)$ for $\mathrm{b}-\mathrm{ACP}$ versus $6.1 \%$ (95\% CI, 3.7-9.7) for u-ACP; $P=.80$ (Figure 2). Rates of TND were instead different, but without reaching statistical significance, between the 2 groups: 8.8\% (95\% CI, 6.3-12.2) for b-ACP versus 7.1\% (95\% CI, 4.5-11.1) for $\mathrm{u}-\mathrm{ACP} ; P=.46$ (Figure 3 ).

\section{Metaregression Analysis of Moderators}

Age, sex, and cardiopulmonary bypass duration did not influence effect size estimates. As expected, rates of both mortality and PND were significantly higher for longer CA times (Q model 18.6, $P<.0001$; and Q model 34.2, $P<.0001$ ) and 
TABLE 1. Overview of publications included in the meta-analysis

\begin{tabular}{|c|c|c|c|c|c|}
\hline Reference & First author & Center(s) & Operative era & Type of ACP & Sample size \\
\hline Ann Thorac Surg. 2006;81:868-74 & Olsson & Uppsala, Sweden & 2001-04 & Bilateral & 48 \\
\hline Ann Thorac Surg. 2006;81:868-74 & Olsson & Uppsala, Sweden & 2001-04 & Unilateral & 1 \\
\hline Eur J Cardiothorac Surg. 2010;38:46-51 & Krahenbuhl & Bern, Switzerland & 2004-07 & Bilateral & 162 \\
\hline Eur J Cardiothorac Surg. 2010;38:46-51 & Krahenbuhl & Bern, Switzerland & 2004-07 & Unilateral & 118 \\
\hline Circulation. 2011;124:434-43 & Kruger & German Registry & 2006-09 & Bilateral & 453 \\
\hline Circulation. 2011;124:434-43 & Kruger & German Registry & 2006-09 & Unilateral & 628 \\
\hline Ann Thorac Surg. 2010;90:547-54 & Leshnower & $\begin{array}{r}\text { Emory HC System, } \\
\text { Atlanta, Georgia }\end{array}$ & 2004-09 & Unilateral & 412 \\
\hline J Korean Med Sci. 2009;24:807-11 & Lee & Seoul, South Korea & $2000-07$ & Unilateral & 104 \\
\hline Heart Lung Circ. 2009;18:334-36 & Numata & New Lambton, Australia & 2005-08 & Unilateral & 21 \\
\hline Eur J Cardiothorac Surg. 2010;37:669-76 & Saritas & Ankara, Turkey & 2002-07 & Unilateral & 50 \\
\hline Ann Thorac Surg. 2002;73:1837-42 & Tasdemir & Ankara, Turkey & 1996-01 & Unilateral & 104 \\
\hline Texas Heart Inst J. 2006;33:310-5 & Yilik & Izmir, Turkey & 2001-04 & Unilateral & 68 \\
\hline Eur J Cardiothorac Surg. 2006;29:1036-40 & Panos & Geneva, Switzerland & 2001-05 & Unilateral & 25 \\
\hline Eur J Cardiothorac Surg. 2012;41:185-91 & Urbanski & Bad Neustadt, Germany & 2005-09 & Unilateral & 347 \\
\hline Ann Thorac Surg. 1999;67:1874-8 & Bachet & Suresnes, France & 1984-98 & Bilateral & 171 \\
\hline Perfusion. 2002;17:187-9 & Colangelo & Milan, Italy & 1999-01 & Bilateral & 37 \\
\hline Ann Thorac Surg. 2006;81:1358-64 & Della Corte & Napoli, Italy & 1997-04 & Bilateral & 202 \\
\hline Ann Thorac Surg. 2003;76:1181-9 & Di Eusanio & $\begin{array}{l}\text { Bologna, Italy; Nieuweigen, } \\
\text { The Netherlands; } \\
\text { Hamamatsu, Japan }\end{array}$ & 1995-02 & Bilateral & 588 \\
\hline Eur J Cardiothorac Surg. 2010;38:293-8 & Estrera & Houston, Texas & 2005-07 & Bilateral & 30 \\
\hline Interact Cardiovasc Thorac Surg. 2009;9:426-30 & Forteza & Madrid, Spain & 1990-08 & Bilateral & 23 \\
\hline Cardiovasc Surg. 2001;9:396-402 & Jacobs & Maastricht, Germany & 1995-00 & Bilateral & 50 \\
\hline Scand Cardiovasc J. 2005;39:87-90 & Kaneda & Osaka, Japan & 1995-03 & Bilateral & 51 \\
\hline J Thorac Cardiovasc Surg. 2008;135:908-14 & Khaladj & Hannover, Germany & 1999-06 & Bilateral & 501 \\
\hline Ann Thorac Cardiovasc Surg. 2003;9:174-9 & Matalanis & Melbourne, Australia & 1996-00 & Bilateral & 25 \\
\hline Eur J Cardiothorac Surg. 2003;23:771-5 & Numata & Nagoya, Japan & 1998-02 & Bilateral & 120 \\
\hline Ann Thorac Surg. 2005;80:1297-302 & Ochiai & Shimonoseki, Japan & 1988-03 & Bilateral & 46 \\
\hline Ann Thorac Surg. 2007;83:805-10 & Sasaki & Osaka, Japan & $2000-05$ & Bilateral & 305 \\
\hline Asian Cardiovasc Thorac Ann. 2009;17:500-4 & Toyama & Yokkaichi, Japan & 2006-08 & Bilateral & 26 \\
\hline Ann Thorac Surg. 2003;76:1951-6 & Ueda & Tokyo, Japan & 1993-01 & Bilateral & 103 \\
\hline Ann Thorac Surg. 1998;66:493-9 & Veeragandham & Chicago, Illinois & 1986-96 & Bilateral & 20 \\
\hline Ann Thorac Surg. 2011;91:1868-74 & Zierer & Frankfurt, Germany & 2000-09 & Bilateral & 245 \\
\hline
\end{tabular}

$A C P$, Antegrade cerebral perfusion.

in case of nonelective operation (Q model 21.5, $P<.0001$; and $\mathrm{Q}$ model 19.1, $P<.0001$; Figure 4). As shown in Table 2, both these variables were similar between the 2 groups $(P=.86$ for mean CA time and $P=.68$ for nonelective surgery); thus they did not affect the meta-analysis.

In addition, meta-regression analysis for $\mathrm{CA}$ temperature showed slightly higher rates of mortality and PND for higher CA temperatures (Q model 7.3, $P=.007$ for mortality, and Q model 14.8, $P=.0001$ for PND). Also mean CA temperature did not differ between groups $(P=.79$; see Table 2), so neither trend could affect the meta-analysis.

The Egger test excluded publication bias for mortality $(P=.29)$, PND $(P=.45)$, and TND $(P=.12)$.

\section{Subanalysis of the Outcomes}

To deal with potential selection bias resulting from the retrospective nature of the source studies, we performed separate subanalyses of more homogeneous papers. First of all, not every study reported equally defined mortality:
TABLE 2. Baseline characteristics of the study population

\begin{tabular}{|c|c|c|c|}
\hline & u-ACP & b-ACP & $\begin{array}{c}P \\
\text { value }\end{array}$ \\
\hline Time frame, $\mathrm{y}$ & 1996-2009 & 1986-2009 & $\mathrm{n} / \mathrm{a}$ \\
\hline Patients, $\mathrm{n}$ & 1505 & 3595 & $\mathrm{n} / \mathrm{a}$ \\
\hline Age, y & $59.4 \pm 6.4$ & $63.3 \pm 3.5$ & .34 \\
\hline Nonelective surgery, n (\%) & $849(56.4)$ & $2135(59.4)$ & .68 \\
\hline Acute aortic dissections, $\mathrm{n}(\%)$ & $385(25.6)$ & $928(25.8)$ & .91 \\
\hline Total arch replacement,* n $(\%)$ & $183 / 759(24.1)$ & $764 / 2892(26.4)$ & .21 \\
\hline Concomitant AV surgery, $\mathrm{n}(\%)$ & $259(17.2)$ & $679(18.9)$ & .16 \\
\hline Concomitant CABG, n (\%) & $147(9.7)$ & $345(9.6)$ & .95 \\
\hline Concomitant MV surgery, $\mathrm{n}(\%)$ & $16(1.1)$ & $44(1.2)$ & .75 \\
\hline $\mathrm{CPB}$ time, $\min$ & $173.7 \pm 47.3$ & $196.7 \pm 42.4$ & .17 \\
\hline CA time, $\min$ & $30.5 \pm 12.3$ & $30.6 \pm 18.7$ & .86 \\
\hline CA temperature, ${ }^{\circ} \mathrm{C}$ & $23.7 \pm 2.4$ & $23.1 \pm 1.5$ & .79 \\
\hline
\end{tabular}




\section{Meta-an alysis of Mortality}

Event rate and $95 \%$ Confidence intervals
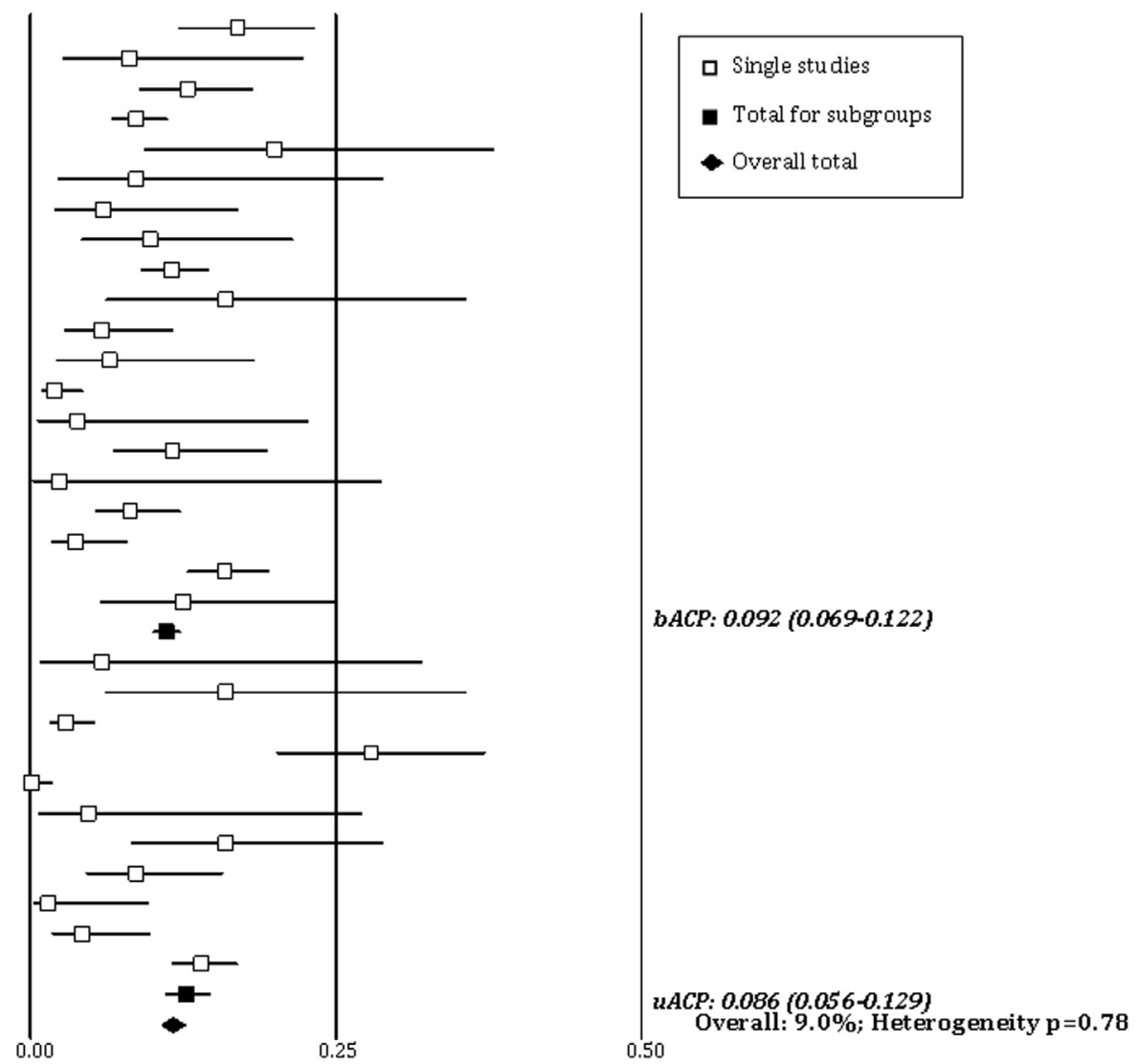

FIGURE 1. Meta-analysis of 30-day mortality. $b A C P$, Bilateral antegrade cerebral perfusion; $u A C P$, unilateral antegrade cerebral perfusion.

most of them reported hospital mortality, and only a few (Kruger 2011, Lee 2009, Saritas 2010, Estrera 2010, and Khaladj 2008; see Table 1 for references) reported 30-day mortality. When excluding these last 5 articles from the meta-analysis, we found no significant changes, and risk of mortality was still similar between groups $(8.2 \%$ for $b-$ ACP vs $7.6 \%$ for u-ACP; $P=.44$ ).

Results did not change significantly when removing studies reporting the earliest series from the 1980s (Bachet 1999, Ochiai 2005, and Veerangandham 1998) nor when removing the 10 studies including fewer than 50 patients (Olsson 2006, Numata 2009, Panos 2006, Colangelo 2002, Estrera 2010, Forteza 2009, Matalanis 2003, Ochiai 2005, Toyama 2009, and Veerangandham 1998).

In conclusion, 1 more subanalysis was performed removing those papers reporting on both types of cerebral protection (Olsson 2006, Krahenbuhl 2010, and Kruger 2011), but even this did not yield different results.

\section{DISCUSSION}

The main finding of the present meta-analysis is the absence of any significant difference between b-ACP and
$\mathrm{u}$-ACP, either in terms of mortality or in terms of cerebral morbidity, when adopting cerebral protection strategies to perform aortic surgery. Besides these principal results, we also analyzed the influence of several cofactors such as the duration and temperature of the $\mathrm{CA}$ and the nonelective status of the operation. As obviously expected, longer times of CA and urgent and/or emergency operations showed the higher risk for both mortality and permanent neurologic dysfunction.

\section{Role of Hypothermia}

One interesting point is the higher risk of mortality and PND found among higher temperatures of $\mathrm{CA}$, which can reflect the real cornerstone importance of hypothermia in performing complex aortic surgery. Most reports about moderate hypothermia $^{9,10}$ showed good results, but longer (more than 40 minutes) and more complex (total arch replacement) operations seem to need a more profound degree of hypothermia in combination with cerebral perfusion. ${ }^{12}$

Accordingly, 1 main finding of the present meta-analysis is the independent association between CA temperature and major outcomes (mortality and PND), regardless of every other operative factor. Nonetheless, CA temperature itself 
Meta-an alysis of PND

Event rate and $95 \%$ Confidence intervals
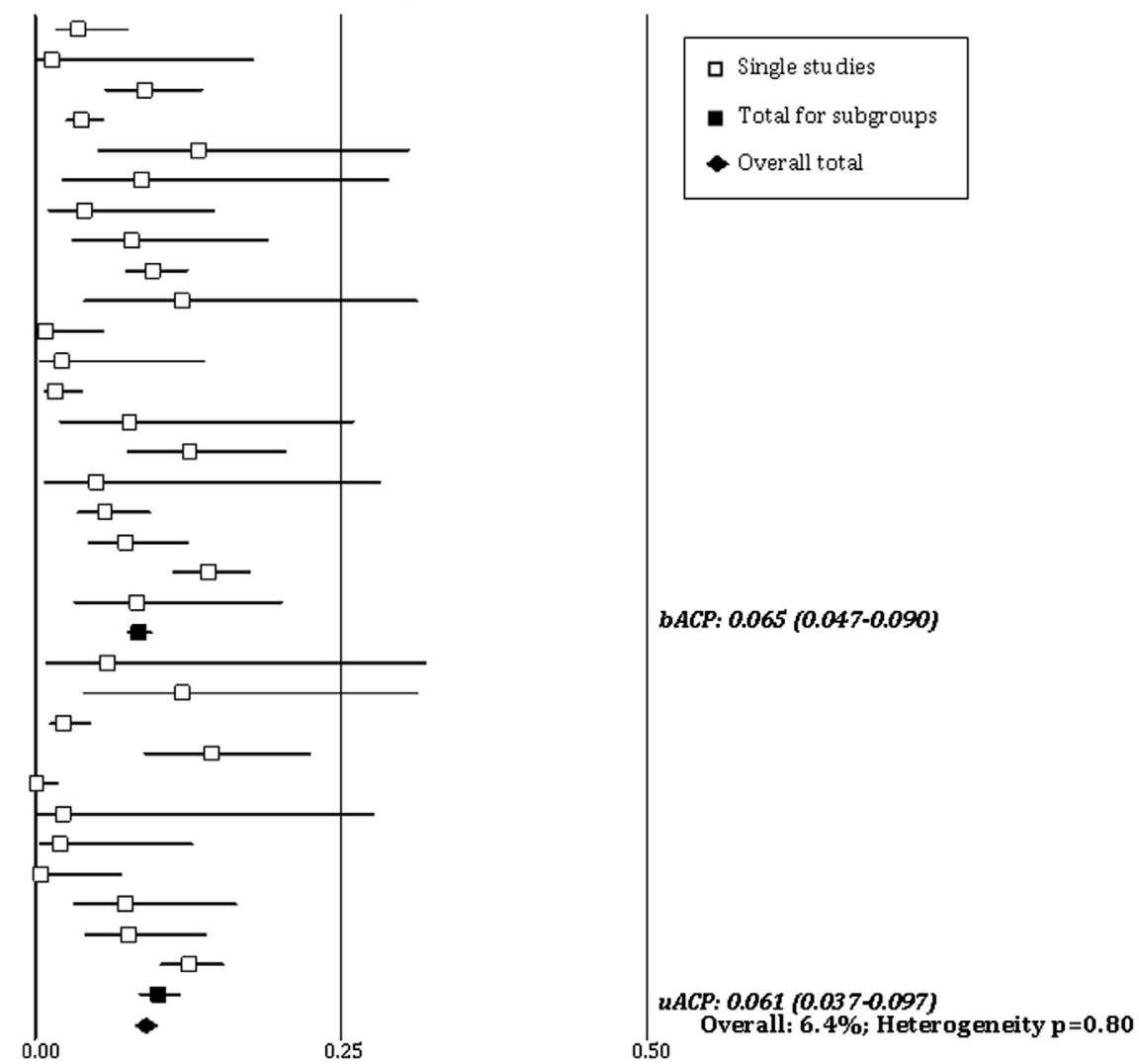

FIGURE 2. Meta-analysis of postoperative permanent neurologic dysfunction $(P N D)$. Event rate and $95 \%$ confidence intervals. $b A C P$, Bilateral antegrade cerebral perfusion; $u A C P$, unilateral antegrade cerebral perfusion.

does not guarantee a "safe period" of CA long enough to perform more than 1 anastomosis, which means that total or partial reimplantation of the supra-aortic vessels definitely requires $\mathrm{ACP} .^{7-10}$

Furthermore, assessment of TND is not univocal, showing some degree of intravariability and intervariability among source publications. This could be a reason explaining why temperature does not affect the rate of TND. Anyway, mortality and PND have to be considered the main outcomes of interest (because they are certainly assessed), whereas TND has not to be considered a strong outcome (many articles do not report them at all).

\section{Pros and Cons of Cerebral Perfusion Strategies}

Previous studies comparing b-ACP and $\mathrm{u}-\mathrm{ACP}^{12-14}$ are discordant and ineffectual to reach a final conclusion. The first of those ${ }^{13}$ was published back in 2006 and involved only 65 patients. It has to be pointed out that, before propensity matching, there is a stunning difference in mortality rates between $\mathrm{b}-\mathrm{ACP}(12 \%)$ and $\mathrm{u}-\mathrm{ACP}(1 \%)$, then avoided by the statistical method. The second study ${ }^{14}$ is a bigger and later one ( $\mathrm{n}=280$ patients, published in 2010$)$, which only found an improved quality of life among patients receiving b-ACP, but not significantly lower rates of mortality and/or neurologic complications. Finally, the last report of the German Registry for Acute Aortic Dissection Type A, ${ }^{12}$ published in 2011 and including 1081 patients, showed equivalent outcomes for b-ACP and u-ACP: standing on this latest and largest comparative study, there is no difference in performing cerebral protection with b-ACP or $\mathrm{u}-\mathrm{ACP}$.

Nevertheless, many surgeons prefer bilateral perfusion because of the minimal complexity it adds to the operation and despite the risk of embolization connected with this technique, which requests bilateral manipulation of the supra-aortic vessels. In fact, the dislodgment of debris and air is a concern during intubation of the supra-aortic vessels in the settings of b-ACP. This problem is instead partially avoided in $\mathrm{u}$-ACP by cannulation of the axillary or subclavian artery and clamping of only the brachiocephalic trunk. An additional clamp can be placed at the origin of the left common carotid artery, avoiding the possibility of the steal phenomenon but increasing the degree of supra-aortic vessel manipulation. 


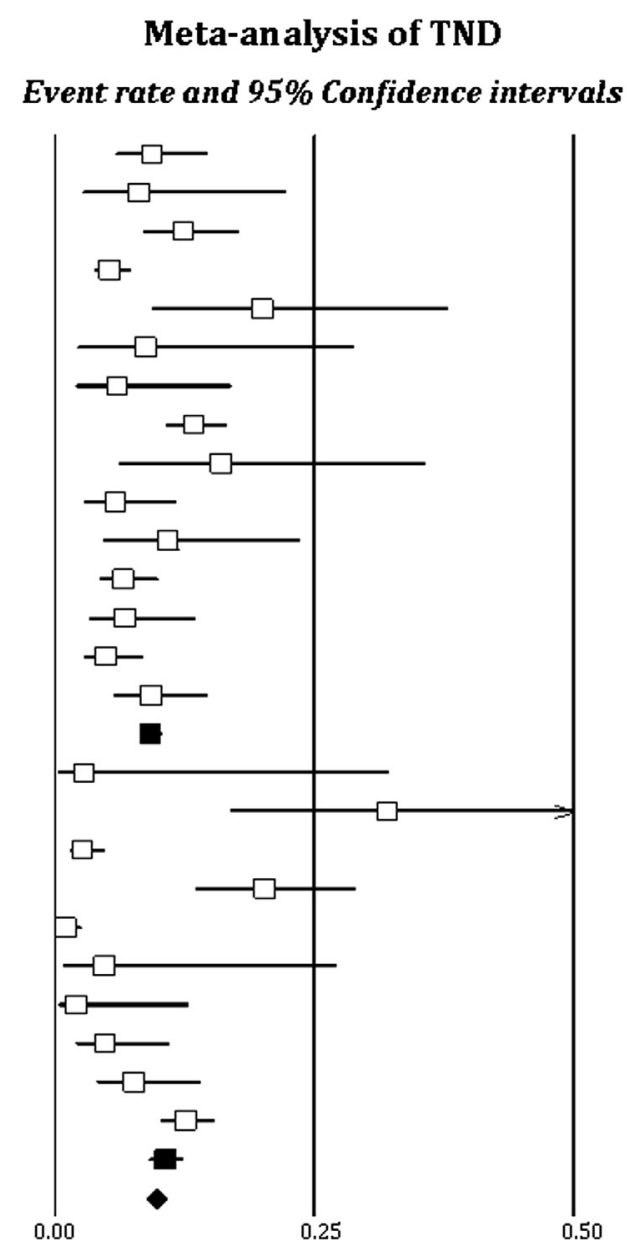

bACP: $0.088(0.063-0.122)$

uACP: $0.071(0.045-0.111)$

Overall: $8.1 \%$; Heterogen eity $p=0.46$

FIGURE 3. Meta-analysis of postoperative temporary neurologic dysfunction (TND). Event rate and $95 \%$ confidence intervals. $b A C P$, Bilateral antegrade cerebral perfusion; $u A C P$, unilateral antegrade cerebral perfusion.

On the other hand, according to anatomic studies, $15 \%$ of patients have a circle of Willis that is incompletely closed ${ }^{15}$; however, in u-ACP via the right axillary artery, the right vertebral artery and extracranial collaterals are also perfused, so that cerebral malperfusion in the context of u-ACP has been rare in clinical experience, and several groups have reported impressive results. ${ }^{16-20}$

In addition, the left vertebral artery arises directly from the aortic arch in nearly $10 \%$ of normal persons, ${ }^{21}$ meaning more rarely than circle of Willis incompleteness $(15 \%$ reported). Unilateral cerebral protection provides perfusion of right vertebral artery and right common carotid artery, thus ensuring good flow to the brain. An abnormal left vertebral artery may alter cerebral flows with a steal phenomenon that can be prevented with separate clamping of each left supra-aortic vessel (carotid, subclavian, and abnormal left vertebral arteries).

Taking into account all these considerations, most surgeons prefer $\mathrm{u}-\mathrm{ACP}$ when a shorter CA time is anticipated, fearing to perform a total arch replacement (with its consequent longer CA duration) with the aid of unilateral cerebral protection. From this meta-analysis, it is evident that the CA duration time itself is a risk factor for both mortality and PND, regardless of the cerebral perfusion adopted. Finally, after interventions on the thoracic aorta with $\mathrm{CA}$, the only factor to influence the postoperative outcome appears to be the degree of hypothermia during the arrest; in fact, lower risks of both mortality and PND were found among patients who underwent more profound hypothermia, again regardless of the cerebral perfusion strategy used.

\section{CONCLUSIONS}

The present meta-analysis, including more than 5000 patients, shows that there is no difference in outcomes between u-APC and b-ACP.

Three main operative factors (higher temperature, longer arrest time, and nonelective status of the operation) were found to be correlated with an increase of both mortality and PND rates after surgery, regardless the ACP strategy adopted. 


\section{Meta-regression of non-elective status on Mortality}

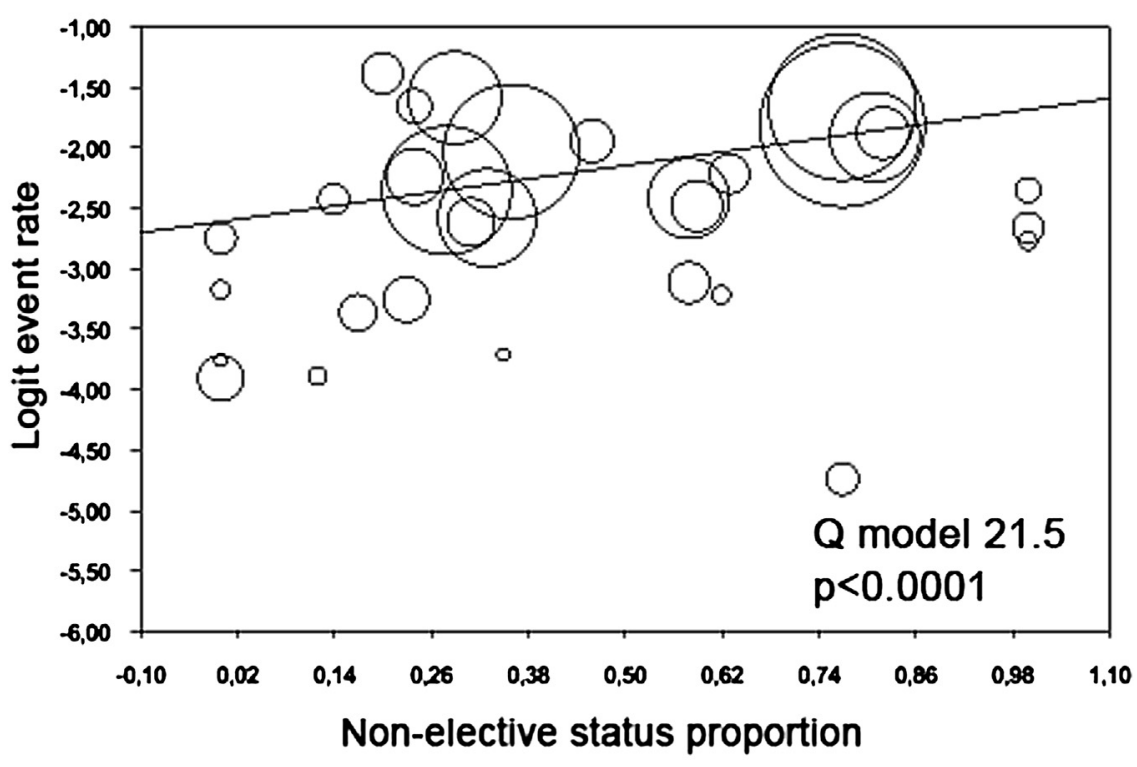

Meta-regression of non-elective status on PND

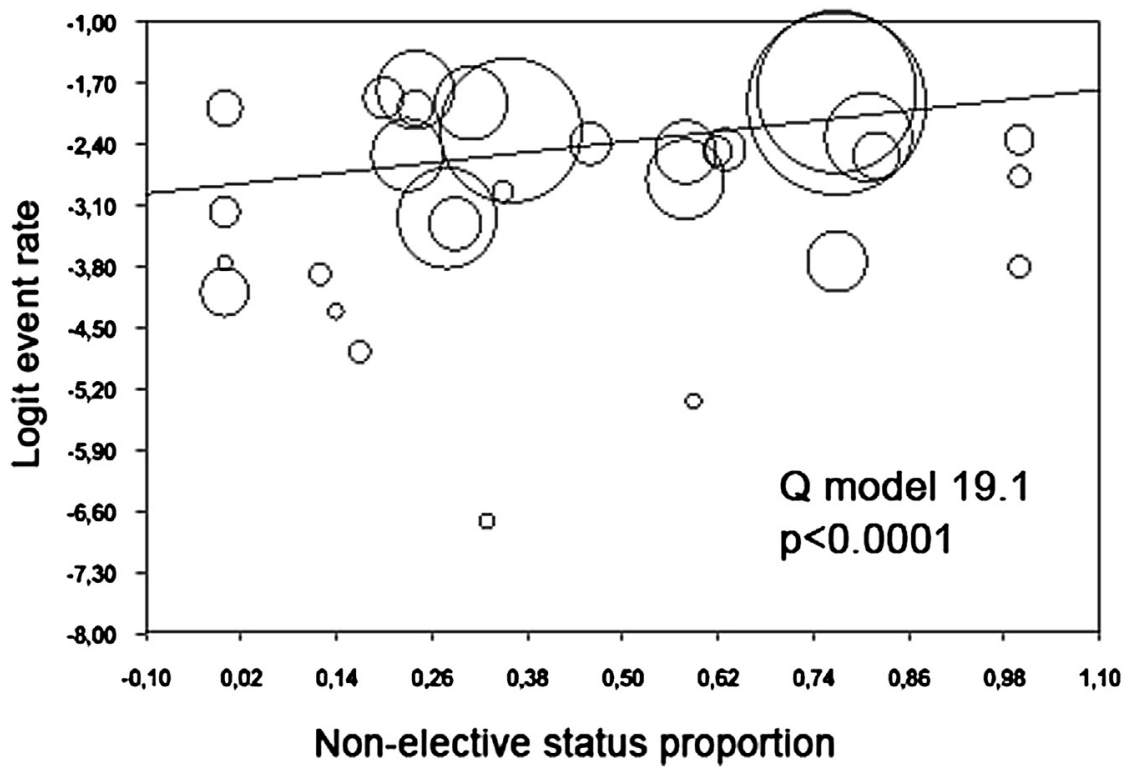

FIGURE 4. Meta-regression analysis of nonelective status of the operation as a moderator for mortality and permanent neurologic dysfunction ( $P N D)$. Circles indicate individual studies, and radii are proportional to relative study weight.

\section{Limitations}

The main limitation of this meta-analysis is the retrospective nature of the source publication. As a counterpoint, it has to be outlined that no randomized trials are available on this topic. Retrospectiveness, indeed, is a potential selection bias; but, on the other hand, the similarity of baseline characteristics (shown in Table 2) and the similar results showed by subanalysis of more homogeneous groups make the comparison fair and reliable, although its conclusions are not completely generalizable to every other setting.

Indications for surgery were heterogeneous, involving chronic aneurysms as acute dissections and hemiarches as total arch procedures. In addition, including acute dissections, preoperative neurologic status was not always available. Both of these potential biases affect either b-ACP or $\mathrm{u}-\mathrm{ACP}$ cohorts and thus should not significantly affect the results. 
Moreover, the use of b-ACP and u-ACP depended on the institution's policy and not on a specific indication; however, similarity of baseline characteristics of the 2 groups of patients (age, cardiopulmonary bypass time, CA time, and nonelective surgery proportion) makes the comparison reliable and fair.

Finally, several surgeons, in the absence of clear evidence, perfuse the left subclavian artery as well to avoid spinal cord injury. This outcome was reported only in a small minority of articles, which is the reason that it was not investigated.

\section{References}

1. Hagl C, Ergin MA, Galla JD, Lansman SL, McCullough JN, Spielvogel D, et al. Neurologic outcome after ascending aorta-aortic arch operations: effect of brain protection technique in high risk patients. J Thorac Cardiovasc Surg. 2001;121: 1107-21.

2. Ergin MA, Griepp EB, Lansman SL, Galla JD, Levy M, Griepp RB. Hypothermic arrest and other methods of cerebral protection during operations on the thoracic aorta. J Card Surg. 1994;9:525-37.

3. Griepp RB, Stinson EB, Hollingsworth JF, Buehler D. Prosthetic replacement of the aortic arch. J Thorac Cardiovasc Surg. 1975;70:1051-63.

4. Strauch JT, Spielvogel D, Haldenwang PL, Haldenwang PL, Zhang N, Weisz D, et al. Impact of hypothermic selective cerebral perfusion compared with hypothermic cardiopulmonary bypass on cerebral hemodynamics and metabolism. Eur J Cardiothorac Surg. 2003;24:807-16.

5. Mexrow CK, Sadeghi AM, Gandsas A, Shiang HH, Levy D, Green R, et al. Cerebral blood flow and metabolism in hypothermic circulatory arrest. Ann Thorac Surg. 1992;54:609-15.

6. Svensson LG, Crawford ES, Hess KR, Coselli JS, Raskin S, Shenaq SA, et al. Deep hypothermia with circulatory arrest: determinants of stroke and early mortality in 656 patients. J Thorac Cardiovasc Surg. 1993;106:19-28.

7. Kazui T, Washiyama N, Muhammad BA, Terada H, Yamashita K, Takinami M. Improved results of atherosclerotic arch aneurysm operations with a refined technique. J Thorac Cardiovasc Surg. 2001;121:491-9.
8. Griepp RB. Cerebral protection during aortic arch surgery. J Thorac Cardiovasc Surg. 2001;121:425-7.

9. Zierer A, Aybek T, Risteski P, Dogan S, Wimmer-Greinecker G, Moritz A. Moderate hypothermia ( 30 degrees $\mathrm{C}$ ) for surgery of acute type A aortic dissection. Thorac Cardiovasc Surg. 2005;53:74-9.

10. Leshnower BG, Myung RJ, Kilgo PD, Vassiliades TA, Vega JD, Thourani VH et al. Moderate hypothermia and unilateral selective antegrade cerebral perfusion: a contemporary cerebral perfusion strategy for aortic arch surgery. Ann Thorac Surg. 2010;90:547-54.

11. Stroup DF, Berlin JA, Morton SC, Olkin I, Williamson GD, Rennie D, et al. Metaanalysis of observational studies in epidemiology: a proposal for reporting. Metaanalysis Of Observational Studies in Epidemiology (MOOSE) group. JAMA 2000;283:2008-12.

12. Krüger T, Weigang E, Hoffmann I, Blettner M, Aebert H. Cerebral protection during surgery for acute aortic dissection type A: results of the German Registry for Acute Aortic Dissection Type A (GERAADA). Circulation. 2011;124: 434-43.

13. Olsson C, Thelin S. Antegrade cerebral perfusion with a simplified technique: unilateral versus bilateral perfusion. Ann Thorac Surg. 2006;81:868-74.

14. Krahenbühl ES, Clement M, Reineke D, Czerny M, Stalder M, Aymard T, et al Antegrade cerebral protection in thoracic aortic surgery: lessons from the past decade. Eur J Cardiothorac Surg. 2010;38:46-51.

15. Merkkola P, Tulla H, Ronkainen A, Soppi V, Oksala A, Koivisto T, et al. Incomplete circle of Willis and right axillary artery perfusion. Ann Thorac Surg. 2006 82:74-9.

16. Numata S, Thomson DS, Seah P, Singh T. Simplified cerebral protection using unilateral antegrade cerebral perfusion and moderate hypothermic circulatory arrest. Heart Lung Circ. 2009;18:334-6.

17. Saritas A, Kervan U, Vural KM, Kucuker SA, Yavas S, Birincioglu LC. Viscera protection during moderately hypothermic selective antegrade cerebral perfusion through right brachial artery. Eur J Cardiothorac Surg. 2010;37:669-76.

18. Tasdemir O, Sarıtas A, Kucuker S, Ozatik MA, Sener E. Aortic arch repair with right brachial artery perfusion. Ann Thorac Surg. 2002;73:1837-42.

19. Yilik L, Emrecan B, Kestelli M, Ozsoyler I, Lafci B, Yakut N, et al. Direct versus side-graft cannulation of the right axillary artery for antegrade cerebral perfusion. Tex Heart Inst J. 2006;33:310-5.

20. Panos A, Murith N, Bednarkiewicz M, Khatchatourov G. Axillary cerebral perfusion for arch surgery in acute type A dissection under moderate hypothermia Eur J Cardiothorac Surg. 2006;29:1036-40.

21. Weinberg PM. Aortic arch anomalies. J Cardiovasc Magn Res. 2006;8:633-43. 